\title{
New Avenues for Theoretical Contributions in Enterprise Architecture Principles - a Literature Review
}

\author{
Mohammad Kazem Haki, Christine Legner \\ Faculty of Business and Economics (HEC), University of Lausanne, CH-1015 Lausanne, \\ Switzerland \\ \{kazem.haki, christine.legner\}@unil.ch
}

\begin{abstract}
Enterprise Architecture (EA), which has been approached by both academia and industry, is considered comprising not only architectural representations, but also principles guiding architecture's design and evolution. Even though the concept of EA principles has been defined as the integral part of EA, the number of publications on this subject is very limited and only a few organizations use EA principles to manage their EA endeavors. In order to critically assess the current state of research and identify research gaps in EA principles, we focus on four general aspects of theoretical contributions in IS. By applying these aspects to EA principles, we outline future research directions in EA principles nature, adoption, practices, and impact.
\end{abstract}

Keywords: enterprise architecture (EA), EA principles, literature review

\section{Introduction}

Enterprise architecture (EA) is a constantly evolving research subject that has been approached by both academia and industry $[1,2]$ over more than two decades. In the existing literature, most papers cite the ANSI/IEEE STD 1471-2000 and define architecture as:

- "the fundamental organization of a system, embodied in its components, their relationships to each other and the environment,

- and the principles governing its design and evolution."

According to aforementioned definition, EA artifacts include not only (1) representation models, which are conceptualized by means of different EA methods, meta-models and frameworks, but also (2) principles, which are rules guiding architecture's design and evolution [3-5]. EA principles are thus integral part of EA definition; Hoogervorst [6] even equates architecture with principles and defines EA as a set of design principles.

Even though the concept of EA principles has been defined as the essential element of EA [3-14], the number of publications on this subject is surprisingly very limited, as outlined by previous studies $[3,4,14,15]$. This is particularly surprising if we compare the number to the vast body of literature related to the first part of the EA definition. Similarly, although principles are described in frameworks such as 
TOGAF [16], only few organizations use them to manage their EA efforts [3]. The EA principles are hence rather underexplored in EA research.

Given the relevance of EA principles, the main objective of this paper is to (1) critically assess the current state of research in this field, (2) identify research gaps, and (3) outline future research directions. To this aim, we suggest a research framework that applies generic IS research types and questions [17] to EA principles and identifies EA principles nature, practices, adoption, and impact as main areas of research. Based on a systematic literature review, our analysis delineates several areas that remain underserved in the existing body of knowledge and that offer researchers the opportunity to contribute to the development of the field of research on EA principles.

The remainder of this paper is structured as follows. First, we provide an overview of the research methodology and analysis framework. The subsequent section describes in detail the results of the literature review. Afterwards, based on the discussed results, we derive underserved theoretical contributions. Finally, we summarize our findings and propose further research.

\section{Research methodology and analysis framework}

\subsection{Analysis framework}

A literature review can either deal with a mature topic or an emerging issue [18]. In this paper, we use it to investigate the emerging issue of EA principles. Recognizing the suggestions of Webster and Watson [18] and Fettke [19], we use a literature review framework for guiding literature analysis and for classifying the papers based on their theoretical contributions. Our research questions are built on the research objectives. This paper aims at identifying underserved theory types in EA principles with regard to primary goals of the theory in IS i.e. description, explanation, prediction, and prescription [17]. Therefore, relying on Gregor's taxonomy of theory types in information systems [17] and in line with other studies [20], our literature review framework focuses on four rigorous research questions and applies them to EA principles (fig. 1):

- Understanding the nature of EA principles: What are EA principles? This research question focuses on the "what" and addresses the definition and characteristics of the phenomena of interest. It results in theory type I (theory for analyzing) of Gregor's taxonomy [17]. As the most basic type of theory, descriptive theories are needed when nothing or little is known about phenomena in question. This theoretical effort results in classification schema, frameworks, taxonomies, or typologies.

- EA principles adoption: Why and to what extent are EA principles adopted? The second research question considers the theory for understanding and explaining how and why some phenomena occur. In other words, this aspect of the analysis framework concerns different approaches of analyzing adoption and diffusion of 
EA principles in different organizational context and EA designs [21]. This will ultimately lead to insights into adoption patterns and the factors that determine successful implementations of EA principles. Answering this research question requires researchers to conduct empirical studies and to collect observations from the field. It results in theory type II (theory for explaining) of Gregor's taxonomy [17].

- EA principles practices: How to design, implement and manage EA principles? This research question aims at specifying how organizations should develop, deploy and manage EA principles, and might be most valuable from the practitioner's point of view. It is associated with a constructivist type of research or design science, resulting in methods and justificatory theoretical knowledge in the development of the discussed phenomena. Gregor [17] classifies this type of theory as theory type $\mathrm{V}$ (theory for design and action).

- EA principles impact: What are the impacts of EA principles? The last research question considers the theoretical constructs and relationships among them. In EA principles like EA itself, measuring the impacts and organizational benefits of principles are of importance. This research question results in theory type IV (theory for explaining and predicting) of Gregor's taxonomy [17].

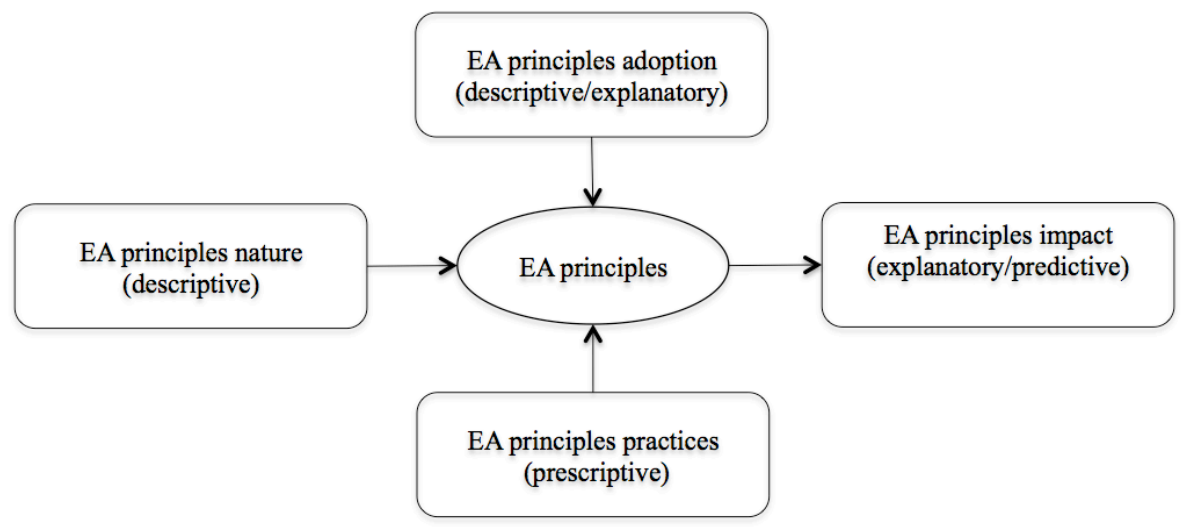

Fig. 1. Analysis framework derived from [17]

\subsection{Literature selection and review process}

In order to analyze prior research results in the field of EA principles, we carried out a comprehensive literature review of scientific journal and conference publications based on the guideline provided by Webster and Watson [18]. We focused on peerreviewed publications and excluded other types of publications (e.g. books, project or research reports) to ensure the quality of the contributions. A set of key terms ("principle", "architecture principle", "design principle", "guideline") was utilized to identify the related publications in EA[M] context articles. Hence, we excluded articles addressing principles in other fields (e.g. modeling $[22,23]$ or SOA). Owing 
to the paucity of publications in EA principles, we did not imply any limitation for publication date.

We identified the related articles by scanning scientific databases (AIS electronic library, ACM Digital Library, DBPL, EBSCOhost, IEEE Xplore Digital Library, Science Direct, Web of Science, and SpringerLink) as well as EA conferences (AIS supported conferences and TEAR workshop). The first step of our literature review resulted in nineteen articles investigating EA principles.

In the subsequent step, we coded and analyzed the identified articles according to a coding scheme. The coding scheme was built on the research questions of the presented analysis framework in section 2.1. In line with [14], our coding scheme also included the level of universality of proposed principles (either generic or company-specific) and emphasis on principles (either as core or among other topics). We included additional codes for research methodology based on the taxonomy of [24] (see Appendix).

\section{Results}

This section provides a general overview of the identified articles and their utilized research methodologies. We also provide a content classification based on our literature review framework so as to analyze their area of theoretical contributions.

\subsection{Overview}

We identified nineteen articles investigating EA principles, twelve of which published in conference proceedings and seven in journals. Richardson et al. [10] is the most cited paper dating back to 1990. It was the initiator of EA principles research, since it was the first to investigate EA principles as the core subject of interest. In 1999, Armour et al. [12] argued the importance of EA principles in the context of EA frameworks. As of 2004 researchers decided to concentrate on this research subject. The time-wise turning points in EA principles are 2006 and 2011, with four articles in each point. To date, twelve articles studied EA principles as the core of their research $[3-5,7-11,14,15,25,26]$ and seven articles investigate them among other topics [6, 12, 13, 27-30]. According to Google Scholar, the articles with focus on EA principles are mostly low cited (less than 20 citations), two average-cited (20-80 citations) and only one is high cited (more than 80 citations).

\subsection{Content classification}

We coded the identified articles based on four theory types of EA principles, presented in our analysis framework. The analysis of the codes provides us with further insights into current state of theoretical contributions in EA principles. 


\section{Nature of EA principles}

All the identified nineteen papers laid emphasis on either EA principles nature or EA principles practices. They all investigated at least one of the aspects related to the nature of EA principles ("what are EA principles?"). This may be explained by the fact that EA principles are in their infancy in EA research; investing a great deal of research on fundamental concept and definitions is hence inevitable.

Since little is known about EA principles in EA research, prior work mostly concentrated on EA principles nature through: (1) suggesting an exhaustive and comprehensible definition of EA principles and shedding light on the role of principles [3-6, 8, 9, 11-15]; (2) discussing the formulation and statement of EA principles, as a set of constraints on the syntax and semantics of EA principles documentation [7, 10, 11, 26]; (3) categorizing EA principles into different areas and scope [10, 25-27]; (4) suggesting a set of EA principles, which are either generic or company (context)-specific [10, 26, 28-30]. We thus reveal four streams of research related to the nature of EA principles namely EA principles definition and role, EA principles documentation, EA principles classification, and EA principles proposition.

EA principles definition

Seven out of nineteen identified papers either provided definitions of EA principles or consolidated existing ones so as to propose a comprehensible definition $[3-5,8,9,14$, 15]:

Architectural design vs. architectural representation: Stelzer [14] distinguishes architectural design (as the conceptual model of the system) from architectural representation (as formal description of architecture). The principles related to architectural design are so-called design principles and the principles regarding architectural representation are denoted as representation principles. Winter and Aier [3], Fischer et al. [4] and Aier et al. [5] similarly argue that EA artifacts include not only representation models, but also design principles. Representation models are described by means of different EA methods, meta-models and frameworks in baseline and target architecture. They are complemented by design principles which are guidelines and rules guiding architecture's design and evolution from baseline to target architecture. Lindström [26] makes a similar distinction by differentiating syntactical (representation) and semantic (design) principles.

Scientific principles vs. normative principles: Scientific and normative principles are distinguished by $[8,9,15]$. The scientific principles are cross-disciplinary, which are applicable in various design principles. The normative principles are based on artifacts such as strategy and environment, and influence other artifacts such as guidelines, requirements, and implementation. The EA principles are thus seen as normative principles.

Architecture principles vs. design principles: Architecture principles utilize a heuristic approach, are included in the architecture of a class of systems, and are inductive in nature. Conversely, design principles are included in the design of a specific system, and are deductive in nature $[8,9,15]$.

Lindström [26] defines architecture principles from the resource management perspective, as the underlying general rules and guidelines for the use of IT resources all through the organization. Stelzer [14] investigates EA principles in a network of 
principles comprising IT, business, organization, application, software architecture, data, and technology principles. He also lays emphasis on "constraint" as another concept that helps assessing the principles" scope and validity. Architecture principles are also discussed in TOGAF [16]. Open Group defines architecture principle as a qualitative statement of intent that should be met by the architecture.

Although Richardson et al. [10] define the principles as guidelines and rationales for the constant examination and re-evaluation of the proposed IT target plan, Stelzer [14] and OptLand and Proper [25] found that no accepted definition of EA principles has yet emerged. Fischer et al. [4] and Aier, Fischer et al. [5] hence considered different definition notions of EA principles and consolidated them into a common understanding that we summarized them as follows:

EA principles, which can be attributed to different architectural layers, are based on business and IT strategies and refer to the construction of an organization. Each EA principle is described in a principle statement. It consists of a rationale that explains why the principle is helpful to attain the pre-determined goal, as well as implications that describe how to implement the given principle. Finally, metrics should be identified for each principle to measure its fulfillment.

EA principles role

Four papers argued the role of EA principles either in EA or in EA-related topics [6, 11-13]. They discuss the role of principles in EA frameworks [12] and enterprise integration and interoperability [13]. Van Bommel et al. [11] regarded EA principles as a means to realize the regulative nature of EA. They hence investigated the regulative goals and requirements of EA so as to propose a formulation structure for EA principles documentation. Hoogervorst [6] equated architecture with principles and viewed architecture as a consistent set of design principles in four areas i.e. business, organization, information, and technology.

EA principles documentation

EA principles documentation concerns the structure used for documenting and communicating principles. Each EA principle document could be made up of different sections namely statement $[7,10,26]$, rational (motivation) $[10,26]$, implication [10, 26], measures [26], and comments [26]. Different guidelines also have been suggested to formulate and document principles. Lindström [26] argues that principles should be consistent, verifiable, unambiguous, modifiable, stable, and complete and correct. According to the TOGAF [16], understandability, robustness, completeness, consistency and stability are also of importance.

\section{EA principles classification}

Four papers covered principles classification [10, 25-27], in which researchers mostly suggested architectural layer-based approach in defining principles implications: Richardson et al. [10] defined principles in organization, application, data, and infrastructure areas; Winter and Fischer [27] placed principles in business, process, integration, software, and technology layers; OptLand and Proper [25] illustrated principles implication in enterprise engineering architectural layers namely business, informational, and datalogical. Moreover, Lindström [26] classified the proposed company-specific principles in governance, outsourcing, risk management, security, 
system management, environment, standardization, and infrastructure categories. Since the latter was built on a single case study, the proposed classification is not generalizable.

EA principles proposition

There are only two studies proposing a set of EA principles. They both utilized case studies and thus identified a set of detailed company-specific principles: Richardson et al. [10] explored EA principles in Texaco and Star Enterprise case. They also provided rationale for each principle and stated the practical implications that result from principles. Lindström [26] developed a set of architecture principles for the Vattenfall case.

Three other studies proposed a set of generic principles in which EA principles have been studied among other subjects (in EA context), notably e-government [29], enterprise transformations [30], and adaptive EA [28]. Wilkinson [28] is the only one proposing adaptable principles in EA, which are modularity, simplification, integration, and standardization.

\section{EA principles practices}

When it comes to EA principles practices, six papers [3-5, 11, 15, 25] investigated the question regarding "how to design, implement, and manage EA principles." They can be categorized into two different lenses: (1) the generic process of determining or extracting principles $[3-5,15]$; (2) managing the life cycle of principles so as to turning principles into an effective means in guiding EA design $[3,11,15,25]$. We thus reveal two streams of research in EA principles practices namely EA principles extraction and EA principles management.

\section{EA principles extraction}

This research stream investigates how to arrive at a set of principles for EA design. Greefhorst and Proper [15] examined different sources for finding principle motivations and formulated six types of drivers which are goals, values, issues, risks, potential rewards and constraints. From a practitioner survey, Winter and Aier [3] identified business strategy as the main source of extracting principles. Two other studies came to the same conclusion through one [4] or two [5] small case studies.

\section{EA principles management}

Recently Greefhorst and Proper [15] proposed a generic process to handle life cycle of architecture principles. They proposed eight sub-processes to handle architecture principles: determine drivers, determine principles, specify principles, classify principles, validate and accept principles, apply principles, manage compliance, and handle changes. Van Bommel et al. also [11] proposed three steps in managing principles, which are assessing needs, formulating principles, and preparing principles deployment. According to a survey, Winter and Aier [3] elicited the process of communicating and updating principles as the main practical issues in EA principles management. 


\section{EA principles adoption}

Since EA principles are underexplored in EA research, there was a tendency to clarify the fundamental concept and practices, but we did not identify any research on principles adoption. This implies that we have neither empirical evidences how EA principles are adopted nor about the factors determining EA principles adoption.

\section{EA principles impact}

Interestingly, there is also no dedicated study investigating the impact of EA principles in prior research, but their expected impacts have been argued implicitly. Some examples are as follows.

The steering and directing role of EA is done by means of principles [7, 25, 31], which are both normative constraints (restrictions) and guidance in EA design [8, 25]. The EA principles also realize the regulative role of EA by considering EA as a set of principles to constrain the enterprise design space [11]. In other words, architecture principles bridge the gap between strategic intentions and concrete design decisions $[8,9,26]$ by addressing concerns of the key stakeholders within an organization [7]. OptLand and Proper [25] also argued that EA principles impact different architectural views of enterprise engineering.

\subsection{Research methodologies}

Since EA principle is an emerging topic in EA research, the majority of prior research either provided conceptual insights or utilized cases study. Nine out of nineteen papers developed conceptual descriptions [6-9, 11-13, 15, 25] relying on author's experience or thought. Case studies were preferred choice for empirical study in eight papers $[4,5,10,26-30]$. Two out of those case studies were mostly literature reviews with one [4] or two [5] very small case descriptions. We also identified one literature review [14] as well as one survey [3] of 70 Swiss and German practitioners on the usage and management of EA principles.

\section{Discussion and findings- new avenues of theoretical contributions}

Based on the discussed results, the current state of research in EA principles reveals various gaps in different dimensions of our analysis framework. In this section, we derive underserved research areas in order to clarify the required research directions (table 1). 


\subsection{Understanding the nature of EA principles: What are EA principles?}

Related to EA principles definition, prior research either provided basic definition or tried to consolidate existing definitions. There is a consensus that EA principles are integral part of EA, can be classified based on architectural layers, and should comprise statement, rationale, implication and measures. Whereas our understanding related to EA principles definition and documentation is maturing, we know very little about specific EA principles and their quality. Prior work proposed either companyspecific principles, which may not be generalizable, or generic principles, which are not explicitly studied in EA context. Future research thus should propose and scientifically validate a set of generic EA principles through expert judgment, multiple-case studies or surveys. This provides a common understanding of principles and their expected level of granularity. Developing a typology of EA principles (based on e.g. EA's requirements, expected goals and outcomes) may support this endeavor. In this regard, analyzing the literature for principles in related fields, such as organizational design or software architecture could be beneficial [14].

Table 1. Current status and future research in EA principles

\begin{tabular}{|c|c|c|}
\hline $\begin{array}{l}\text { Fields of theoretical } \\
\text { contributions }\end{array}$ & Current status & Future research \\
\hline Nature & $\begin{array}{l}\text { Consensus on EA } \\
\text { principles definition } \\
\text { and documentation }\end{array}$ & $\begin{array}{l}\text { - Propose and validate generic EA principles and/or } \\
\text { typologies of EA principles }\end{array}$ \\
\hline Practices & $\begin{array}{l}\text { Tentative or implicit } \\
\text { processes for } \\
\text { principles extraction } \\
\text { and management }\end{array}$ & $\begin{array}{l}\text { - Methodologies for identifying possible sources of } \\
\text { extracting principles } \\
\text { - Management processes to handle the life cycle of } \\
\text { principles from extraction to assessment } \\
\text { - Integration of EA principles in IT management and } \\
\text { governance methodologies }\end{array}$ \\
\hline Adoption & No research yet & $\begin{array}{l}\text { - Understanding of the adoption process } \\
\text { - EA principles institutionalization } \\
\text { - EA principles embeddedness in EA design } \\
\text { - Success factors of EA principles adoption }\end{array}$ \\
\hline Impact & $\begin{array}{l}\text { Implicit } \\
\text { argumentations }\end{array}$ & $\begin{array}{l}\text { - Role of EA principles in shaping the design of EA } \\
\text { - Relationship between deploying EA principles and } \\
\text { EA effectiveness / organizational benefits }\end{array}$ \\
\hline
\end{tabular}

\subsection{EA principles practices: How to design, implement and manage EA principles?}

Drawing on theory type V (theory for design and action) of Gregor's taxonomy[17], this category comprises design-oriented research related to the design, implementation, and management of EA principles.

Concerning the design of EA principles, the small portion of prior research [3-5, 15] either proposed a tentative process or implicitly looked into it. Key stakeholders must understand how the motivation behind a set of principles aligns with the 
organization's strategies and its micro and macro environment. Further investigation needs to be carried out in order to explore the possible sources of extracting EA principles such as higher organizational levels, industry standards, external authorities [25]. Future research should also investigate principles alignment with business and IT strategies as well as the influence of contextual and organizational factors on extracting EA principles.

Regarding the management of EA principles, a scientifically validated management process covering the entire life cycle is lacking. Owing to the relative newness of EA principles in EA research, also no research has been conducted on their implementation practices. For developing appropriate practices in EA principles, multiple-case studies are recommended to gather real-world experiences on: (1) how to translate business and IT strategies into an exhaustive set of EA principles, and (2) how to turn them into a set of rules, guidelines and standards guiding EA design. More design-oriented research is required to engineer methodologies supporting companies in identifying EA principles as well as managing their life cycle.

When it comes to EA principles implementation, different approaches in establishing and enforcing EA principles are concerned. The EA principles implementation considers clear organizational accountability for adhering to principles so as to ensure they are used to guide design decisions. Given the nature of EA principles as governing EA design and evolution (cf. ANSI/IEEE STD 1471-2000 definition of architecture), more research is thus needed to study how EA principles complement IT management and governance methodologies.

\subsection{EA principles adoption: Why and to what extent are EA principles adopted?}

We did not identify any systematic research on EA principles adoption, which concerns acceptance, diffusion, success and influence factors, and measurement of EA principles.

Above all, we are lacking a comprehensible understanding of the adoption process of EA principles. It could be studied either as a stand-alone phenomenon or as a part of EA adoption. If EA principles adoption is considered as stand-alone phenomenon, questions related to the operationalization in organizational processes are of interest. It is recommended that future research investigates organizational adoption of EA principles through general management theories, such as institutional theory, structuration theory, or contingency theory. For understanding EA principles acceptance by organizations and individuals, different theoretical lenses, such as diffusion of innovation or technology acceptance model are useful.

When considering EA principles as inherent to EA adoption, future research needs to investigate the embeddedness of EA principles. EA adoption $[21,32,33]$ is a rather new topic in EA research concerning EA institutionalization throughout the organization. Given the context-dependent nature of EA in different organizational settings [21], it is also recommended that future research propose and validate archetype-specific principles.

Winter and Aier [3] also identified that difficulties to enforce EA principles are related to the inability to measure EA principle implementation. In order to address 
this gap, metrics need to be defined to assess the measurable implementation of EA principles.

According to aforementioned discussion, we propose research streams in EA principles adoption as follows: EA principles institutionalization, EA principles embeddedness in EA design, measurement model for EA principles adoption, and success and influence factors on principles adoption. Regarding the proposed research directions, qualitative (case studies) and large-scale quantitative research for further analysis are recommended.

\subsection{EA principles impact: What are the impacts of EA principles?}

Similar to EA principles adoption, we did not identify any research on EA principles impact, but only implicit assumptions expressed by the rationale for selecting certain EA principles.

References to ANSI/IEEE STD 1471-2000 definition of architecture, EA principles govern the design and evolution of EA. The future research in EA principles impact hence could be derived from these two aspects.

The design of EA could be considered as either generic EA frameworks and patterns [32, 34-37] or situational EA designs [21, 38, 39]. Future research could use both perspectives, i.e. generic or situational EA designs, to analyze the impact of principles in ruling and guiding EA design and evolution.

Since principles are considered as an effective means to shape EA design, this brings us to the impact of principles on EA evolution and effectiveness. In effect, EA principles are used to guarantee the expected outcomes out of EA. The future research could thus study the causal relationship between deploying EA principles and EA effectiveness. This could be part of a larger causal model that also illustrates the impact of EA effectiveness on organizational benefits. Accordingly, the impact of EA principles on organizational benefits could be studies either directly or through their impact on EA effectiveness as a mediate variable.

\section{Summary and conclusion}

This paper profiles the existing research on EA principles based on four research questions concerning EA principles nature, adoption, practices, and impact. Our analysis of nineteen articles has shown that existing research has mostly concentrated on EA principles definition as well as on the guidelines to document principles. Despite the fact that EA principles are highly relevant, we know relatively little about specific principles and how they should be designed, implemented, and managed. The existing research also has no illustration on how design principles are adopted and how they alter an existing architecture.

Figure 2 shows a research model representing the relationships between our proposed research directions in EA principles. According to ANSI/IEEE STD 14712000, EA principles are served as a means to govern the design and evolution of EA that finally lead to a set of organizational benefits. In other words, to purposefully 
design and manage EA and meet the expected organizational outcomes, each EA endeavor could be ruled and guided by EA principles. This also implies that EA principles only create organizational benefits, if they are properly implemented. Our research model is hence composed of four dimensions to guarantee organizational benefits.

Regarding EA principles, several topics are recommended for future research (as discussed in previous section): methodologies for identifying the possible sources of extracting EA principles, management processes to handle the life cycle of EA principles from extraction to deployment, real world experiences in principles implementation, proposing and validating a set of generic EA principles, and understanding the embeddedness of EA principles in organizational structure and processes.

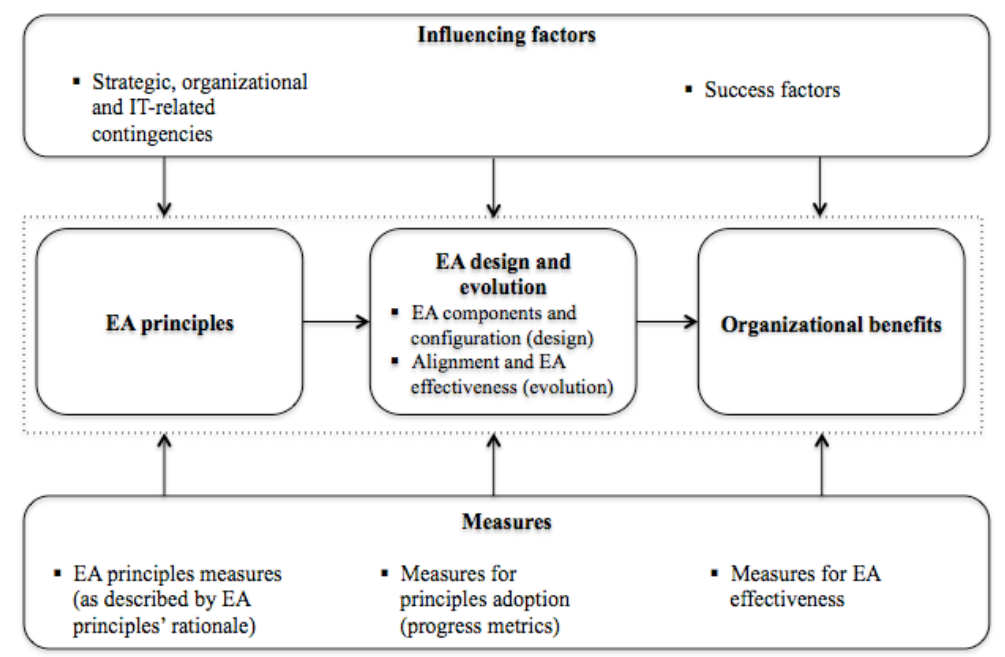

Fig. 2. General research outline in EA principles

Concerning the impact of principles on EA design and evolution, two topics are of interest: (1) EA design: Impact of EA principles on EA components and configuration comprising all aspects of implementing EA in the organization e.g. phases, governance, and modeling [21, 40]; (2) EA evolution: Impact of EA principles on EA effectiveness so as to foster consistency and integration between different architectural layers. The latter also describes business-IT alignment through adapting EA design to a specific organizational context.

The influencing factors consist of the success factors fostering the adoption of EA principles as well as contingency (contextual) factors influencing the effect of EA principles on EA design and evolution. In effect, EA design has to adhere to a set of contextual factors $[21,32,40,41]$. Therefore, the effect of contextual factors could be investigated through proposing a set of EA design-specific principles for situational EA designs.

Finally, our research model suggests developing a set of measures to assess the success of EA principles adoption, the level of achievement to each of proposed 
generic or design-specific principles, the effectiveness of EA design, and organizational benefits resulting from EA.

\section{References}

1. Niemi, E.: Enterprise Architecture Stakeholders - a Holistic View. AMCIS 2007 Proceedings. 41, 2-9 (2007).

2. Radeke, F.: Awaiting Explanation in the Field of Enterprise Architecture Management. Presented at the Americas Conference on Information Systems (AMCIS 2010) , Lima, Peru (2010).

3. Winter, R., Aier, S.: How are Enterprise Architecture Design Principles Used? Presented at the The Fifteenth IEEE International EDOC Conference Workshops, Trends in Enterprise Architecture Research (TEAR), Helsinki (2011).

4. Fischer, C., Winter, R., Aier, S.: What is an Enterprise Architecture Design Principle? Towards a Consolidated Definition. Computer and Information Science 2010. pp. 193205. Springer (Berlin, Heidelberg) (2010).

5. Aier, S., Fischer, C., Winter, R.: Construction and Evaluation of a Meta-Model for Enterprise Architecture Design Principles. Wirtschaftinformatik Proceedings 2011. 51, 637-644 (2011)

6. Hoogervorst, J.: Enterprise Architecture: Enabling Integration, Agility And Change. International Journal of Cooperative Information Systems. 13, 213-233 (2004).

7. Van Bommel, P., Hoppenbrouwers, S., Proper, H.A., Weide, T.P.: Giving Meaning to Enterprise Architectures: Architecture Principles with ORM and ORC. In: Meersman, R., Tari, Z., and Herrero, P. (eds.) On the Move to Meaningful Internet Systems 2006: OTM 2006 Workshops. pp. 1138-1147. Springer Berlin Heidelberg, Berlin, Heidelberg (2006).

8. Proper, E., Greefhorst, D.: The Roles of Principles in Enterprise Architecture. In: Proper, E., Lankhorst, M.M., Schönherr, M., Barjis, J., and Overbeek, S. (eds.) Trends in Enterprise Architecture Research. pp. 57-70. Springer Berlin Heidelberg, Berlin, Heidelberg (2010).

9. Proper, E., Greefhorst, D.: Principles in an Enterprise Architecture Context. Journal of Enterprise Architecture. 7, 8-16 (2011).

10. Richardson, G.L., Jackson, B.M., Dickson, G.W.: A Principles-Based Enterprise Architecture: Lessons from Texaco and Star Enterprise. MIS Quarterly. 14, 385-403 (1990).

11. Van Bommel, P., Buitenhuis, P., Hoppenbrouwers, S., Proper, E.: Architecture principles A regulative perspective on enterprise architecture. Presented at the 1st International Workshop on Enterprise Modelling and Information Systems Architectures (EMISA) (2007).

12. Armour, F.J., Kaisler, S.H., Liu, S.Y.: A big-picture look at enterprise architectures. IT Professional. 1, 35-42 (1999).

13. Chen, D., Doumeingts, G., Vernadat, F.: Architectures for enterprise integration and interoperability: Past, present and future. Computers in Industry. 59, 647-659 (2008).

14. Stelzer, D.: Enterprise Architecture Principles: Literature Review and Research Directions. In: Dan, A., Gittler, F., and Toumani, F. (eds.) Service-Oriented Computing. ICSOC/ServiceWave 2009 Workshops. pp. 12-21. Springer Berlin Heidelberg, Berlin, Heidelberg (2010).

15. Greefhorst, D., Proper, E.: A Practical Approach to the Formulation and Use of Architecture Principles. Presented at the 15th IEEE International Enterprise Distributed Object Computing Conference Workshops (EDOCW) (2011). 
16. Open Group: TOGAF Version 9 - The Open Group Architecture Framework. The Open Group (2009).

17. Gregor, S.: The Nature of Theory in Information Systems. MIS Quarterly. 30, 611-642 (2006).

18. Webster, J., Watson, R.T.: Analyzing the past to prepare for the future: Writing a literature review. MIS Quarterly. 26, 13-23 (2002).

19. Fettke, P.: State-of-the-Art des State-of-the-Art: Eine Untersuchung der Forschungsmethode „Review“ innerhalb der Wirtschaftsinformatik. WIRTSCHAFTSINFORMATIK. 48, 257-266 (2006).

20. Viering, G., Legner, C., Ahlemann, F.: The (Lacking) Business Perspective on SOACritical Themes in SOA Research. Tagungsband der Konferenz Wirtschaftsinformatik 2009. pp. 45-54. Österreichische Computer Gesellschaft (2009).

21. Haki, M.K., Legner, C., Ahlemann, F.: Beyond EA Frameworks: Towards an Understanding of the Adoption of Enterprise Architecture Management. ECIS 2012 Proceedings (2012).

22. Balabko, P., Wegmann, A.: Systemic classification of concern-based design methods in the context of enterprise architecture. Information Systems Frontiers. 8, 115-131 (2006).

23. Brown, A.W.: Model driven architecture: Principles and practice. Software and Systems Modeling. 3, 314-327 (2004).

24. Galliers, R.D., Land, F.F.: Viewpoint: choosing appropriate information systems research methodologies. Commun. ACM. 30, 901-902 (1987).

25. OptLand, M., Proper, E.: Impact of principles on enterprise engineering. Presented at the 15th European Conference on Information Systems (2007).

26. Lindström, A.: On the Syntax and Semantics of Architectural Principles. Presented at the 39th Annual Hawaii International Conference on System Sciences (HICSS) (2006).

27. Winter, R., Fischer, R.: Essential Layers, Artifacts, and Dependencies of Enterprise Architecture. Journal of Enterprise Architecture. 3, 1-12 (2007).

28. Wilkinson, M.: Designing an 'adaptive' enterprise architecture. BT Technology Journal. 24, 81-92 (2006).

29. Janssen, M., Kuk, G.: A Complex Adaptive System Perspective of Enterprise Architecture in Electronic Government. Presented at the 39th Hawaii International Conference on System Sciences (HICSS), Hawaii (2006).

30. Nightingale, D.: Principles of enterprise systems. Presented at the Second International Symposium on Engineering Systems MIT , Cambridge, Massachusetts, (2009).

31. OptLand, M., Proper, E., Waage, M., Cloo, J., Steghuis, C.: Enterprise Architecture: Creating Value by Informed Governance. Springer (2008).

32. Hjort-Madsen, K.: Institutional patterns of enterprise architecture adoption in government. Transforming Government: People, Process and Policy. 1, 333-349 (2007).

33. Aier, S., Weiss, S.: An Institutional Framework for Analyzing Organizational Responses to the Establishment of Architectural Transformation. ECIS 2012 Proceedings (2012).

34. Buckl, Ernst, A., Lankes, J., Schneider, K., Schweda, C.: A Pattern based Approach for constructing Enterprise Architecture Management Information Models. Internationale Tagung Wirtschaftsinformatik 2007 - Band 2. 145-162 (2007).

35. Franke, U., Holschke, O., Matthes, F., Schweda, C., Sommestad, T., Ullberg, J., Buckl, S.: A Pattern-based Approach to Quantitative Enterprise Architecture Analysis. AMCIS 2009 Proceedings. 318, 3-11 (2009).

36. Ernst: Enterprise architecture management patterns. Proceedings of the 15th Conference on Pattern Languages of Programs. pp. 7:1-7:20. ACM, Nashville, Tennessee (2008).

37. Schulman, J.: Patterns Play an Essential Role in Enterprise Architecture. Gartner (2004).

38. Aier, S., Gleichauf, B., Winter, R.: Understanding Enterprise Architecture Management Design - An Empirical Analysis. Presented at the Wirtschaftinformatik Proceedings 2011 (2011). 
39. Winter, R.: Design Solution Analysis for the Construction of Situational Design Methods. In: Ralyté, J., Mirbel, I., and Deneckère, R. (eds.) Engineering Methods in the ServiceOriented Context. pp. 19-33. Springer Berlin Heidelberg, Berlin, Heidelberg (2011).

40. Schmidt, C., Buxmann, P.: Outcomes and success factors of enterprise IT architecture management: empirical insight from the international financial services industry. European Journal of Information Systems. 1-18 (2011).

41. Boh, W.F., Yellin, D.: Using Enterprise Architecture Standards in Managing Information Technology. Journal of Management Information Systems. 23, 163-207 (2006). 


\section{Appendix}

Table 2. Coded articles in EA principles based on theoretical contributions, level of study, universality of proposed principles, and research methodologies

\begin{tabular}{|c|c|c|c|c|c|c|c|c|c|c|c|c|c|c|}
\hline \multicolumn{3}{|c|}{ Identified articles } & \multicolumn{9}{|c|}{ Content classification according to analysis framework } & \multirow{3}{*}{ 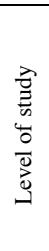 } & \multirow{3}{*}{ 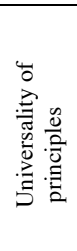 } & \multirow[b]{3}{*}{$\begin{array}{l}\text { Research } \\
\text { method }\end{array}$} \\
\hline & & & \multicolumn{5}{|c|}{ Nature } & \multicolumn{2}{|c|}{ Practices } & \multirow[b]{2}{*}{$\frac{\pi}{0}$} & \multirow[b]{2}{*}{$\begin{array}{l}\overrightarrow{0} \\
\stackrel{\tilde{\Xi}}{\Xi} \\
\text { : }\end{array}$} & & & \\
\hline 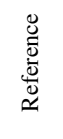 & Author(s) & Title & 总 & $\frac{0}{2}$ & 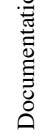 & 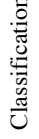 & 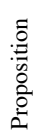 & 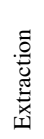 & 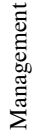 & & & & & \\
\hline$[14]$ & Stelzer & $\begin{array}{l}\text { Enterprise architecture } \\
\text { principles: literature } \\
\text { review and research } \\
\text { directions }\end{array}$ & a & & & & & & & & & 1 & & $\begin{array}{l}\text { Conceptual } \\
\text { (LR) }\end{array}$ \\
\hline [8] & $\begin{array}{l}\text { Proper and } \\
\text { Greefhorst }\end{array}$ & $\begin{array}{l}\text { The roles of principles } \\
\text { in enterprise } \\
\text { architecture }\end{array}$ & a & & & & & & & & & 1 & & Conceptual \\
\hline [9] & $\begin{array}{l}\text { Proper and } \\
\text { Greefhorst }\end{array}$ & $\begin{array}{l}\text { Principles in an } \\
\text { enterprise architecture } \\
\text { context }\end{array}$ & $a$ & & & & & & & & & 1 & & Conceptual \\
\hline$[15]$ & $\begin{array}{l}\text { Greefhorst } \\
\text { and Proper }\end{array}$ & $\begin{array}{l}\text { A practical approach to } \\
\text { the formulation and use } \\
\text { of architecture } \\
\text { principles }\end{array}$ & a & & & & & Q & Q & & & 1 & & Conceptual \\
\hline$[25]$ & $\begin{array}{l}\text { OptLand and } \\
\text { Proper }\end{array}$ & $\begin{array}{l}\text { Impact of principles on } \\
\text { enterprise engineering }\end{array}$ & & & & Q & & & Q & & & 1 & & Conceptual \\
\hline [3] & $\begin{array}{l}\text { Winter and } \\
\text { Aier }\end{array}$ & $\begin{array}{l}\text { How are enterprise } \\
\text { architecture design } \\
\text { principles used? }\end{array}$ & a & & & & & a & Q & & & 1 & & Survey \\
\hline [4] & Fischer et al. & $\begin{array}{l}\text { What is an enterprise } \\
\text { architecture design } \\
\text { principle? Towards a } \\
\text { consolidated definition }\end{array}$ & $a$ & & & & & Q & & & & 1 & & Case study \\
\hline [5] & Aier et al. & $\begin{array}{l}\text { Construction and } \\
\text { evaluation of a meta- } \\
\text { model for enterprise } \\
\text { architecture design } \\
\text { principles }\end{array}$ & a & & & & & Q & & & & 1 & & Case study \\
\hline [26] & Lindström & $\begin{array}{l}\text { On the syntax and } \\
\text { semantics of } \\
\text { architectural principles }\end{array}$ & & & $\alpha$ & O & 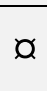 & & & & & 1 & 2 & Case study \\
\hline [7] & $\begin{array}{l}\text { Van Bommel } \\
\text { et al. }\end{array}$ & $\begin{array}{l}\text { Giving meaning to } \\
\text { enterprise architectures: } \\
\text { Architecture principles } \\
\text { with ORM and ORC }\end{array}$ & & & Q & & & & & & & 1 & & Conceptual \\
\hline$[10]$ & $\begin{array}{l}\text { Richardson et } \\
\text { al. }\end{array}$ & $\begin{array}{l}\text { A principles-based } \\
\text { enterprise architecture: } \\
\text { Lessons from Texaco } \\
\text { and Star Enterprise }\end{array}$ & & & 0 & , & व & & & & & 1 & 2 & Case study \\
\hline [11] & $\begin{array}{l}\text { Van Bommel } \\
\text { et al. }\end{array}$ & $\begin{array}{l}\text { Architecture principles } \\
\text { - A regulative } \\
\text { perspective on } \\
\text { enterprise architecture }\end{array}$ & & $\alpha$ & $\alpha$ & & & & O & & & 1 & & Conceptual \\
\hline
\end{tabular}




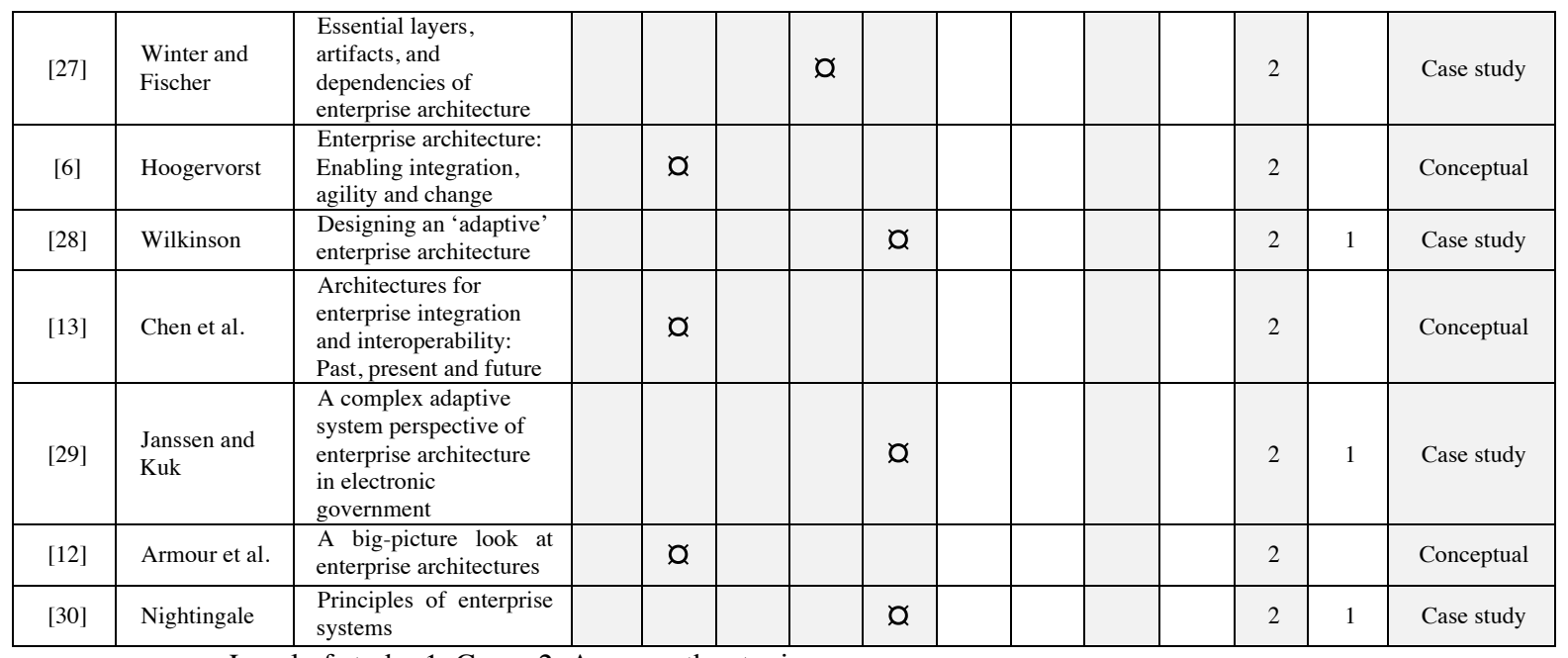

Level of study: 1. Core, 2. Among other topics

Universality of principles: 1. Generic, 2. Company-specific 